\title{
A new tide model for the Mediterranean Sea based on altimetry and tide gauge assimilation
}

\author{
D. N. Arabelos, D. Z. Papazachariou, M. E. Contadakis, and S. D. Spatalas \\ Department of Geodesy and Surveying, Aristotle University of Thessaloniki, 54124 Thessaloniki, Greece
}

Received: 7 September 2010 - Published in Ocean Sci. Discuss.: 30 September 2010

Revised: 6 June 2011 - Accepted: 10 June 2011 - Published: 20 June 2011

\begin{abstract}
The tides for the Mediterranean Sea are described through a high resolution model (MEDI10) developed by assimilation of tide-gauge data and T/P data into a barotropic ocean tide model. Tidal parameters from 56 coastal tidegauge stations around the Mediterranean for eight principal constituents: M2, S2, N2, K2, K1, O1, P1 and Q1 and from 20 stations for M2, S2, K1, O1 are included in the model. TOPEX/Poseidon data with all corrections applied except for the ocean tides and bathymetry from TOPO 13.1 were used for development of the model. Numerical experiments were carried out for the estimation of the friction velocity and of the decorrelation length scale. The experiments related to the friction velocity showed that the use of spatially varying friction velocity, estimated as a function of position in the model domain, gives better results than a constant value. The experiments related to the estimation of the decorrelation length suggest that the results are not sensitive for lengths close to ten times the length of the grid cell. The assessment of the model is based on ten tide-gauge observations that are not used for the assimilation. Comparisons were carried out with contemporary published global or regional models. The final solution is computed using 76 selected coastal tide-gauge stations. The comparison between the observed and the model constituents results in a Root Sum of Squares (RSS) equal to $1.3 \mathrm{~cm}$.
\end{abstract}

\section{Introduction}

Ocean tides especially in closed sea areas can deviate considerably from the theoretical values due to unequal water depths and to the fact that the continents impede the move-

Correspondence to: D. N. Arabelos

(arab@eng.auth.gr) ment of water. Satellite altimetry enabled the development of improved tidal models even in closed sea areas, by assimilating altimeter data into hydrodynamic models. In general, the modern global tidal models can be categorized into three groups: hydrodynamic, empirical, and assimilation models.

Hydrodynamic models are derived by solving the Laplace Tidal Equations (LTE) and using bathymetry data as boundary conditions. Most of hydrodynamic solutions, such as Schwiderski's (1980) and FES94.1 (Le Provost et al., 1994) are undefined in the Mediterranean Sea, due to its bottom morphology and coast complexity (see Fig. 1).

Empirical models are derived by extracting ocean tidal signals from satellite altimetry and they describe the total geocentric ocean tides, which include the ocean loading effect. These models can be used directly in altimetry applications such as ocean tide corrections.

Assimilation models are derived by solving the hydrodynamic equations with altimetric and tide-gauge data assimilation. The tides are constrained by the hydrodynamic equations which must satisfy the tidal fields of elevations and velocities, and the observation data from tide-gauge stations and altimetry. Generalized inverse methods allow the combination in a rational manner all of this information into tidal fields best fitting both the data and the dynamics, in a least squares sense (Bennett, 1992; Egbert et al., 1994).

Basins such as the Mediterranean Sea, which are connected to the oceans through narrow entrances, have small tidal ranges (Pugh, 1987). The areas of entrances are too small for sufficient oceanic tidal energy to enter to compensate for the energy losses which would be associated with large tidal amplitudes. Although the amplitude of the tides in the Mediterranean Sea is small, the use of the currently best tidal model is very essential for many geodetic and geodynamic applications (e.g., Arabelos, 2002).

Published by Copernicus Publications on behalf of the European Geosciences Union. 
The Mediterranean Sea is divided into two large basins separated by the Sicilian Channel and the Messina Strait. The tides of the western basin are strongly influenced by the Atlantic tides which penetrate through the Strait of Gibraltar. Apart from the Strait of Gibraltar, two smaller openings of the Mediterranean to the Bosporus (N-E Aegean) and the Suez (S-E Mediterranean) channels are negligible for tidal propagation studies. The Adriatic and Aegean Seas are connected to the eastern basin through the Straits of Otranto and Crete, respectively. The configuration of the eastern basin is very complicated. The bathymetry of the Mediterranean Sea is quite complex with both the east and west basins being more than $4 \mathrm{~km}$ deep in places (see Fig. 1).

Problems in tidal studies are due to the inadequate number of tide-gauge stations mainly along the south and east coasts of the Mediterranean and in the quality of the existing data. The lack of data from deep areas is balanced by the good quality altimeter data gained e.g. from TOPEX/Poseidon (T/P) and JASON-1.

Among numerous investigations Cartwright and Ray (1990), used direct tidal analysis of the altimetry from the Geosat ERM to derive estimates of the diurnal and semidiurnal oceanic tides. Schrama and Ray (1994), performed harmonic analysis on 12 months of data from the T/P altimeter mission, in terms of corrections to the Schwiderski and Cartwright-Ray models. At the same time, the eight leading ocean tides have been mapped in Asian semienclosed seas by inverting combined sets of tide gauge harmonic constants and a reduced set of T/P altimeter data ( Mazzega and Bergé, 1994). The aim of the work by Matsumoto et al. (1995), was to derive accurate global ocean tide model from T/P sea surface height data of $5 \mathrm{~cm}$ accuracy. TOPEX geophysical data records of cycles 9-94 were analyzed and tidal solutions were obtained for the eight major constituents. Three empirical ocean tide models were determined by Desai and Wahr (1995), from repeat cycles 10-78 of T/P to investigate the effects of the satellite orbit ephemeris on the ocean tides determined from T/P altimetry and the effect of extracting the free core nutation resonance in the definition of the diurnal ocean tide admittance. The comparison of the global ocean tide models based on T/P data, released during 1994, with a common 104 tide gauge data by Andersen et al. (1995), showed that six of them had RMS agreement better than $3 \mathrm{~cm}$. Furthermore, the intercomparison of the models concluded that the RMS agreement between models based on 2 years of T/P altimetry was significantly better than the agreement between models based on 1 year of T/P altimetry. At the end of 1997, the number of the global ocean tide models developed since 1994 as a consequence of precise altimetric measurements from T/P exceeded 20. Shum et al. (1997), provided an accuracy assessment of 10 such models and discussed their benefits in many fields including geodesy, oceanography and geophysics. An upgraded version of the tidal solutions (FES94.1) was presented by Le Provost et al. (1998), obtained by assimilating an altimeter-derived data set in the

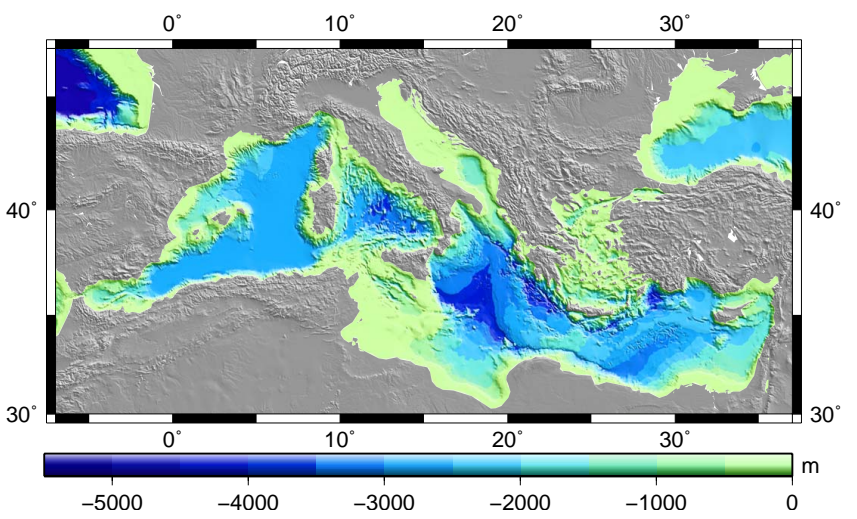

Fig. 1. Bathymetry in the Mediterranean Sea.

finite element hydrographic model, following the representer approach. With the use of accurate data from the newer satellite altimeter missions Jason-1, Jason-2, ENVISAT the quality of the ocean tide models based on accurate altimetry is continously improved.

Contemporary global and regional models such as EOT10a (Bosch and Savcenko, 2010), GOT4.7 (Ray, 1999), FES2004 (Lyard et al., 2006), NAO99.b (Matsumoto et al., 2000), TPXO7.2 (Egbert et al., 1994), MED2008 (Egbert and Erofeeva, 2008), succeed in describing satisfactory the tidal propagation in the main part of the basin, thought the use of an adequate number of coastal data might improve further the up to now achieved quality.

Here we present a new numerical model for the Mediterranean Sea hereinafter referred to as MEDI10. The assimilation method selected for the computation is described in brief in Sect. 2. In Sect. 3 the data used for the computation of the model are described. Details about the tide-gauge observations, their method of analysis and the corresponding results are given in Sect. 4. In Sect. 5 the computed model and its assessment is described. Conclusions and remarks are drawn in Sect. 6.

\section{Method}

For the computation of the tidal model the "Oregon State University Tidal Inversion Software" (OTIS) was used (Egbert and Erofeeva, 2002). The OTIS assimilation method determines the optimal tidal solution that satisfies the tidal dynamics and simultaneously provides the best overall fit to the assimilation observations. More explicitly the goal of the method is to find tidal fields $\mathbf{u}$ consisted both with the hydrodynamic equations

$\mathbf{S u}=\mathbf{f}_{0}$,

where $\mathbf{S}$ is the dynamical equations plus boundary conditions and $\mathbf{f}_{0}$ is the astronomical forcing corrected for solid Earth 
tides, and with a $k$-dimensional vector $\mathbf{d}$ of tidal data

$\mathbf{d}=\mathbf{L u}$.

In (2) $\mathbf{L}=\left[L_{1} \ldots L_{k}\right]$ corresponds to the $k$ measurement functionals relating variables from data space to the unknown tidal space $\mathbf{u}$. Due to measurement errors and inadequacies in the necessarily approximate dynamical equations, there will be in general no $\mathbf{u}$ satisfying both equations. With the generalized inversion approach a compromise between (1) and (2) is achieved by minimizing the quadratic penalty functional

$$
\begin{aligned}
J[\mathbf{d}, \mathbf{u}] & =(\mathbf{L u}-\mathbf{d})^{T} \Sigma_{e}^{-1}(\mathbf{L u}-\mathbf{d}) \\
& +\left(\mathbf{S u}-\mathbf{f}_{0}\right)^{T} \Sigma_{f}^{-1}\left(\mathbf{S u}-\mathbf{f}_{0}\right)
\end{aligned}
$$

where $\Sigma_{e}$ is the measurement error covariance and $\Sigma_{\mathbf{f}}$ is the model covariance error. The penalty function (3) consists of two main terms, the error to the data and the error to the model and the aim is to determine the optimal space $\mathbf{u}$ that minimize the penalty function $J$. If the dynamical equations (1) are linear, the representer approach (Egbert et al., 1994), can be used to minimize (3) according to which representers, i.e. functions showing the impact that a single observation will have on the entire domain, are calculated for a subset of data locations and a solution to the variational problem is sought within the space of linear combinations of calculated representers. The minimizer of (3) can be written as

$\hat{\mathbf{u}}=\mathbf{u}_{0}+\sum_{k=1}^{K} \beta_{k} \mathbf{r}_{k}$,

where $\mathbf{u}_{0}=\mathbf{S}^{-1} \mathbf{f}_{0}$ is the exact solution of (1), the functions $\mathbf{r}_{k}$ are the representers of the data functionals defined by $L_{k}$ and $\beta_{k},(k=1, K)$ are coefficients to be determined.

Representers can be calculated by first solving the adjoint of the dynamical equation

$\mathbf{S}^{T} a_{k}=\Delta_{K}$,

where $\Delta_{k}$ is the averaging kernel for the data functional $L_{k}$, and then solving the forward equation

$\mathbf{S r}_{k}=\Sigma_{\mathbf{f}} a_{k}$

The forcing for (6) is the solution to (5) smoothed by convolution with the dynamical error covariance $\Sigma_{\mathbf{f}}$.

The representer coefficients $\beta_{k}$ are found by solving the $K \times K$ system of equations

$\left(\mathbf{R}+\Sigma_{e}\right) \beta=\mathbf{d}-\mathbf{L u}_{0}$,

where $\mathbf{R}$ is the representer matrix with elements

$R_{j k}+L_{j} \mathbf{r}_{k}$.

To describe the dynamics of the tides, the linearized shallow water equations are used

$$
\begin{aligned}
& \frac{\partial \mathbf{U}}{\partial t}+f \hat{\mathbf{z}} \times \mathbf{U}+g \cdot H \nabla(\zeta-\zeta \mathrm{SAL})+\mathbf{F}=\mathbf{f}_{0}, \\
& \frac{\partial \zeta}{\partial t}=-\nabla \cdot \mathbf{U}, \quad \mathbf{U}=\left[\begin{array}{l}
U \\
V
\end{array}\right],
\end{aligned}
$$

where $U$ and $V$ are the two components of the barotropic transport i.e., the depth-averaged velocity times the depth $H$, $f$ is the Coriolis parameter, $\hat{\mathbf{z}}$ is oriented to the local vertical, $t$ is the time, $\mathbf{F}$ is the dissipative stress, $g$ is the acceleration of gravity, $\zeta$ is the elevation of the sea surface, $\zeta_{\mathrm{SAL}}$ is the tidal loading and self attraction and $\mathbf{f}_{0}$ represents the earth tide.

The linearized OTIS dynamics can be transformed from the time domain into the frequency domain using Fourier transform. In this way the Eq. (9) can be expressed by the following time-independent equations

$\Omega \mathbf{U}+g H \nabla \zeta=\mathbf{f}_{U}$,

$\nabla \cdot \mathbf{U}+i \omega \zeta=\mathbf{f}_{\zeta}$

where

$\Omega=\left[\begin{array}{cc}i \omega+k & -f \\ f & i \omega+k\end{array}\right]$.

Assuming $k \neq 0$ or $\omega \neq f, \Omega$ is invertible at all locations, so that (10) can be written as

$\mathbf{U}=-g H \Omega^{-1} \nabla \zeta+\Omega^{-1} \mathbf{f}_{U}$

and combine this with (11) a second order equation in $\zeta$ is gained

$\nabla \cdot g H \Omega^{-1} \nabla \zeta-i \omega \zeta=\nabla \cdot \Omega^{-1} \mathbf{f}_{U}+\mathbf{f}_{\zeta}$

Solution of (1) can thus be accomplished by solving (13) for $\zeta$, then using the result in (12) to calculate $U$. This provides in brief the basic scheme for solving shallow water equations. The method and its numerical implementation are described in details by Egbert et al. (1994); Egbert and Erofeeva (2002).

\section{Data}

The following data sets were used in this investigation:

- PATHFINDER data base including TOPEX/Poseidon altimeter data for the period 23-09-92-11-08-2002, with no-tidal correction applied.

- TOPO 13.1, the current version of bathymetry model by Smith and Sandwell (1997).

- Tide-gauge data: Hourly values from 59 tide-gauge stations in the Mediterranean Sea (see Fig. 2) were analyzed. In Table 1 details about the coordinates and time coverage of the data are shown.

- Tidal parameters for M2, S2, K1, O1 from 20 tide-gauge stations (not included in the previous data set), extracted from Tsimplis et al. (1995) (see Fig. 2). In Table 2 the coordinates of the data are shown. 


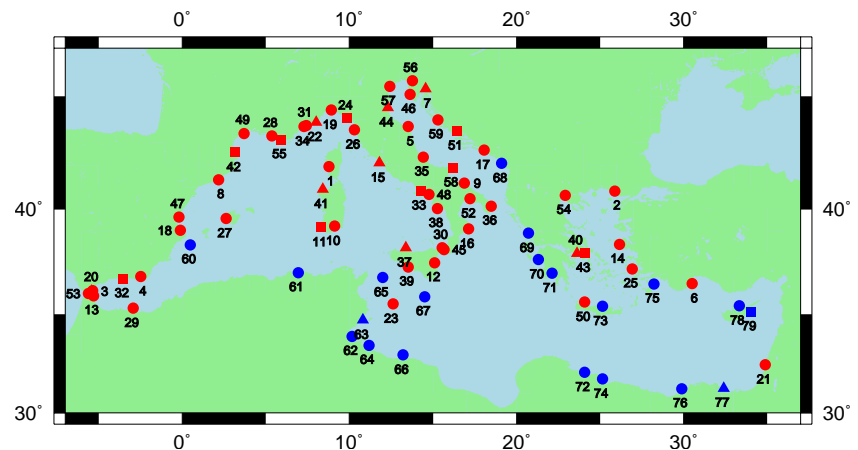

Fig. 2. Distribution of tide-gauge stations along the coasts of the Mediterranean Sea. In red the stations included in Table 1 are shown. For the stations in blue included in Table 2 tidal parameters for M2, S2, K1, and O1 were used from Tsimplis et al. (1995). Filled squares: gauges used in the control data set (i), filled triangles: gauges used in the control data set (ii).

- TPXO7.2 global tidal model.

- The models GOT4.7, EOT10a, NAO99b, FES2004, TPXO7.2 and MED2008 for comparisons and assessment.

TPXO7.2 is a current version of a global model of ocean tides (Egbert and Erofeeva, 2002), which best-fits, in a least-squares sense, the Laplace Tidal Equations and along track averaged data from TOPEX/Poseidon (T/P), TP2, ERS, GRACE, and data from Arctic, Antarctic and Australian tide gauges, obtained with OTIS. The analysis of the model is $1 / 4$ degree. This model is used as correction model providing estimates of residuals in the altimetry data more consistent with typical detided data no matter how many constituents are included in the inverse solution. Only constituents that are in the correction file, but not these to be included in our model are used for corrections. Furthermore, harmonic constants from TPXO7.2 were used for comparison with the results of the analysis of our tide-gauge data and with the harmonic constants taken from Tsimplis et al. (1995).

\section{Analysis of the tide-gauge observations}

Data from 59 tide-gauge stations distributed mostly along the north coasts of the Mediterranean Sea (see Fig. 2), red dots) were available from different organizations as it is shown in Table 1 . These data were hourly values covering time periods from one to almost fifteen years as it is indicated in Table 1 . The analysis of the coastal data was carried out using the "Versatile Harmonic Tidal Analysis" software (Foreman et al., 2009). This software permits more versatility in the harmonic analysis of tidal time series.
Specific improvements to traditional methods include the analysis of randomly sampled and/or multiyear data, more accurate nodal correction, inference and astronomical argument adjustments through direct incorporation into the least squares matrix and correlation matrices and error estimates, using Singular Value Decomposition (SVD) techniques. This approach facilitate decisions on the selection of constituents for the analysis. In mathematical terms, a one-dimensional time series with tidal and no-tidal energies can be expressed by

$$
\begin{aligned}
h\left(t_{j}\right) & =Z_{0}+\sum_{k=1}^{n} f_{k}\left(t_{0}\right) A_{k} \cos \left[\omega_{k}\left(t_{j}-t_{0}\right)\right. \\
& \left.+V_{k}\left(t_{0}\right)+u_{k}\left(t_{0}\right)-g_{k}\right]+R\left(t_{j}\right),
\end{aligned}
$$

where $h\left(t_{j}\right)$ is the measurement at time $t_{j}, Z_{0}$ is a constant, $f_{k}\left(t_{0}\right)$ and $u_{k}\left(t_{0}\right)$ are the nodal corrections to amplitude and phase, respectively, at some reference time $t_{0}$, for major constituent $k$ with frequency $\omega_{k}, A_{k}$, and $g_{k}(k=1, n)$ are the amplitude and phase lag of constituent $k$, respectively, $V_{k}\left(t_{0}\right)$ is the astronomical argument for constituent $k$ at time $t_{0}$, $R\left(t_{j}\right)$ is the no-tidal residual, and $n$ is the number of tidal constituents. To solve for $Z_{0}, A_{k}$ and $g_{k}$, a least squares approach is usually used. The observation times are assumed to arise from hourly sample with gaps permitted. In order to avoid some deficiencies and limitations, the basic equation (14) was replaced by

$$
\begin{aligned}
h\left(t_{j}\right) & =Z_{0}+a t_{j}+\sum_{k=1}^{n} f_{k}\left(t_{j}\right) A_{k} \cos \left[V_{k}\left(t_{j}\right)\right. \\
& \left.+u_{k}\left(t_{j}\right)-g_{k}\right]+R\left(t_{j}\right),
\end{aligned}
$$

where $a$ is a linear trend. According to Foreman et al. (2009), the advantage in this case is that $V, u$ and $f$ are evaluated at the precise times of each measurement, thus eliminating inaccuracies arising from the assumption of a linear variation in the astronomical argument and temporally constant values for the nodal corrections. Furthermore, the linear trend allows for the measurements $t_{j}$ to arise from arbitrary sampling, and permits multi-constituent inferences that are computed directly within the least squares fit.

In the harmonic analysis 15 tidal constituents are included ( $Z_{0}$, MM, MF, Q1, O1, K1, MU2, N2, M2, S2, MK3, SK3, $\mathrm{S} 4,2 \mathrm{SM} 6, \mathrm{M} 8)$. Constituents $\mathrm{P} 1$ and $\mathrm{K} 2$ are inferred from $\mathrm{K} 1$ and $\mathrm{S} 2$, respectively, using their exact amplitude ratio and phase difference relationships relative to K1 and S2, respectively. When accurate inference constants (amplitude ratio and phase difference) are available, inference not only yields amplitudes and phases for the inferred constituents, but also significantly reduces periodic variations in the estimated amplitudes and phases of the reference constituents (Foreman and Henry, 2004). The misfit on the tidal data series analysis for the 59 tide-gauge stations ranges from 8 to $10 \mathrm{~cm}$ depending on the length and the quality of each tidal time series. The SVD approach produces a covariance matrix and 
Table 1. Time period, number of records and sources of tide-gauge stations.

\begin{tabular}{|c|c|c|c|c|c|c|c|}
\hline \multirow{2}{*}{$\begin{array}{l}\text { Station } \\
\text { number }\end{array}$} & \multirow[b]{2}{*}{ Tide-gauge station } & \multirow[b]{2}{*}{ Latitude } & \multirow[b]{2}{*}{ Longitude } & \multicolumn{2}{|c|}{ Time period } & \multirow{2}{*}{$\begin{array}{r}\text { Number of } \\
\text { records }\end{array}$} & \multirow[b]{2}{*}{ Source } \\
\hline & & & & from & to & & \\
\hline 1 & Ajaccio & 41.9228 & 8.7628 & $5-09-2000$ & $1-11-2009$ & 60406 & SONEL \\
\hline 2 & Alexandroupolis & 40.8333 & 25.8833 & 0-02-1986 & $10-12-1987$ & 9876 & HNHS \\
\hline 3 & Algeciras & 36.1167 & -5.4333 & 1-01-1998 & 27-09-2002 & 40234 & IEO \\
\hline 4 & Almeria & 36.8300 & -2.4783 & $1-09-2008$ & $13-03-2010$ & 10387 & $\mathrm{PdE}$ \\
\hline 5 & Ancona & 43.6957 & 13.5089 & $2-01-2006$ & $15-10-2009$ & 32696 & ISPRA \\
\hline 6 & Antalya & 36.4900 & 30.5200 & 1-01-1999 & $25-12-2005$ & 58472 & ESEAS \\
\hline 7 & Bakar & 45.2000 & 14.3000 & $2-10-2004$ & $27-05-2006$ & 14442 & ESEAS \\
\hline 8 & Barcelona2 & 41.3417 & 2.1636 & $1-09-2008$ & $13-03-2010$ & 9796 & PdE \\
\hline 9 & Bari & 41.1844 & 16.8627 & $2-01-2006$ & $15-10-2009$ & 32443 & ISPRA \\
\hline 10 & Cagliari & 39.2102 & 9.1143 & 2-01-2006 & $15-10-2009$ & 32632 & ISPRA \\
\hline 11 & Carloforte & 39.1480 & 8.3095 & $2-01-2006$ & $15-10-2009$ & 32601 & ISPRA \\
\hline 12 & Catania & 37.4981 & 15.0938 & 2-01-2006 & $15-10-2009$ & 32468 & ISPRA \\
\hline 13 & Ceuta & 35.9000 & -5.3167 & $1-01-1995$ & $31-12-2006$ & 104019 & IEO \\
\hline 14 & Chios & 38.3667 & 26.1500 & 5-02-1986 & 5-11-1987 & 10884 & HNHS \\
\hline 15 & Civitavecchia & 42.0940 & 11.7896 & $2-01-2006$ & $15-10-2009$ & 32621 & ISPRA \\
\hline 16 & Crotone & 39.1500 & 17.1700 & 2-01-2006 & 15-10-2009 & 32197 & ISPRA \\
\hline 17 & Dubrovnik & 42.6583 & 18.0633 & 1-01-1999 & $30-12-2005$ & 61344 & ESEAS \\
\hline 18 & Gandia & 39.0157 & -0.1234 & $1-09-2008$ & $13-03-2010$ & 9593 & PdE \\
\hline 19 & Genova & 44.4101 & 8.9255 & 2-01-2006 & $15-10-2009$ & 32490 & ISPRA \\
\hline 20 & Gibraltar & 36.1483 & -5.3650 & $7-02-2009$ & $7-03-2010$ & 9124 & POL \\
\hline 21 & Hadera & 32.4667 & 34.8833 & $6-02-2003$ & $30-04-2007$ & 28914 & UHSLC \\
\hline 22 & Imperia & 43.8783 & 8.0189 & 2-01-2006 & 15-10-2009 & 32424 & ISPRA \\
\hline 23 & Lampedusa & 35.4998 & 12.6044 & 2-01-2006 & $15-10-2009$ & 31597 & ISPRA \\
\hline 24 & La Spezia & 44.0387 & 9.8646 & 4-03-2006 & $15-10-2009$ & 32540 & ISPRA \\
\hline 25 & Leros & 37.2037 & 26.9266 & 1-01-1986 & 29-11-1987 & 14088 & HNHS \\
\hline 26 & Livorno & 43.5463 & 10.2993 & $2-01-2006$ & $15-10-2009$ & 32643 & ISPRA \\
\hline 27 & Mallorca & 39.5603 & 2.6375 & $2-05-2003$ & $31-05-2005$ & 17394 & IEO \\
\hline 28 & Marseille & 43.2788 & 5.3539 & $1-01-2000$ & 27-11-2009 & 84497 & SONEL \\
\hline 29 & Melilla & 35.2906 & -2.9283 & $8-02-2008$ & $13-03-2010$ & 13185 & PdE \\
\hline 30 & Messina & 38.1963 & 15.5635 & $2-01-2006$ & $15-10-2009$ & 32669 & ISPRA \\
\hline 31 & Monaco & 43.7329 & 7.4237 & $8-01-2000$ & $7-12-2009$ & 85917 & SONEL \\
\hline 32 & Motril2 & 36.7203 & -3.5236 & $6-03-2008$ & $14-03-2010$ & 13247 & PdE \\
\hline 33 & Napoli & 40.8300 & 14.2500 & $5-01-2006$ & $15-10-2009$ & 32133 & ISPRA \\
\hline 34 & Nice & 43.6956 & 7.2855 & $1-01-2000$ & 26-11-2009 & 80045 & SONEL \\
\hline 35 & Ortona & 42.3800 & 14.4200 & $2-01-2006$ & $15-10-2009$ & 32714 & ISPRA \\
\hline 36 & Otranto & 40.1471 & 18.5100 & $2-01-2006$ & $15-10-2009$ & 32348 & ISPRA \\
\hline 37 & Palermo & 38.2024 & 13.3821 & $2-01-2006$ & $15-10-2009$ & 32488 & ISPRA \\
\hline 38 & Palinuro & 40.0299 & 15.2753 & 2-01-2006 & $15-10-2009$ & 32628 & ISPRA \\
\hline 39 & Porto Empedocle & 37.2858 & 13.5268 & 4-01-2006 & $15-10-2009$ & 32497 & ISPRA \\
\hline 40 & Pireas & 37.9347 & 23.6212 & 8-01-1986 & $27-12-1987$ & 14712 & HNHS \\
\hline 41 & Porto Torres & 40.9111 & 8.4028 & $2-01-2006$ & $15-10-2009$ & 32357 & ISPRA \\
\hline 42 & Porto Vendres & 42.5536 & 3.1565 & 6-10-2007 & 26-11-2009 & 18188 & SONEL \\
\hline 43 & Rafina & 37.9500 & 24.0833 & 9-01-1986 & $31-12-1987$ & 9372 & HNHS \\
\hline 44 & Ravenna & 44.5016 & 12.3015 & 2-01-2006 & 15-10-2009 & 32381 & ISPRA \\
\hline 45 & Reggio Calabria & 38.1217 & 15.6489 & 2-01-2006 & $15-10-2009$ & 32605 & ISPRA \\
\hline 46 & Rovinj & 45.0833 & 13.6283 & 1-01-1999 & $30-12-2005$ & 61344 & ESEAS \\
\hline 47 & Sagunto & 39.6339 & -0.2061 & $2-09-2008$ & 13-3-2010 & 10709 & $\mathrm{PdE}$ \\
\hline 48 & Salerno & 40.6766 & 14.7508 & 2-01-2006 & 15-10-2009 & 32638 & ISPRA \\
\hline 49 & Sete & 43.3976 & 3.6991 & $1-01-2000$ & 1-11-2009 & 69095 & SONEL \\
\hline 50 & Souda & 35.5975 & 24.0748 & 1-01-1986 & $31-12-1987$ & 14952 & HNHS \\
\hline 51 & Split & 43.3500 & 16.3000 & 1-01-1999 & $30-12-2005$ & 61344 & ESEAS \\
\hline 52 & Taranto & 40.4756 & 17.2238 & $2-01-2006$ & $15-10-2009$ & 32161 & ISPRA \\
\hline 53 & Tarifa & 36.0064 & -5.6036 & 1-01-1994 & $31-12-2005$ & 104503 & IEO \\
\hline 54 & Thessaloniki & 40.6365 & 22.9175 & 2-03-1986 & 5-12-1987 & 12960 & HNHS \\
\hline 55 & Toulon & 43.1229 & 5.9147 & $1-01-2000$ & 26-11-2009 & 82743 & SONEL \\
\hline 56 & Trieste & 45.6000 & 13.7000 & 2-01-2006 & $12-9-2008$ & 22747 & ISPRA \\
\hline 57 & Venezia & 45.4182 & 12.4265 & $2-01-2006$ & $15-10-2009$ & 32630 & ISPRA \\
\hline 58 & Vieste & 41.8881 & 16.1770 & $2-01-2006$ & $15-10-2009$ & 32693 & ISPRA \\
\hline 59 & Zadar & 43.9917 & 15.0500 & 2-01-1991 & $30-12-2005$ & 103045 & ESEAS \\
\hline
\end{tabular}


Table 2. Coordinates of the stations taken from Tsimplis et al. (1995).

\begin{tabular}{clcc}
\hline $\begin{array}{c}\text { Station } \\
\text { number }\end{array}$ & $\begin{array}{l}\text { Tide-gauge } \\
\text { station }\end{array}$ & Latitude & Longitude \\
\hline 60 & Alicante & 38.3388 & -0.4796 \\
61 & Skikda & 37.0211 & 6.9278 \\
62 & Gabes & 33.9076 & 10.1717 \\
63 & Sfax & 34.7103 & 10.8107 \\
64 & Zarzis & 33.4562 & 11.1611 \\
65 & Panteleria & 36.7800 & 11.9900 \\
66 & Tripoli & 32.9629 & 13.2043 \\
67 & Malta & 35.8520 & 14.5360 \\
68 & Bar & 42.0000 & 19.0000 \\
69 & Lefkas & 38.8850 & 20.7097 \\
70 & Katakolo & 37.6404 & 21.3192 \\
71 & Kalamata & 36.9848 & 22.1153 \\
72 & Tobruch & 32.0794 & 24.0587 \\
73 & Iraklion & 35.3880 & 25.1331 \\
74 & Portobardia & 31.7520 & 25.1538 \\
75 & Rodos & 36.4763 & 28.2268 \\
76 & Alexandria & 31.2500 & 29.8900 \\
77 & Portsaid & 31.2779 & 32.4007 \\
78 & Kyrenia & 35.4051 & 33.3175 \\
79 & Famagusta & 35.1154 & 34.0059 \\
\hline
\end{tabular}

correlation coefficients

$r_{j k}=\operatorname{cov}\left(x_{j}, x_{k}\right) /\left[\sigma\left(x_{j}\right) \sigma\left(x_{k}\right)\right]$

that allow a direct method for evaluating the independence of the chosen constituents (Cherniawsky et al., 2001). In Table 3 correlation coefficients larger than 0.01 related to the corresponding station (number in parenthesis) between the constituents $j$ and $k$ of the corresponding covariance matrices are shown. Maximum values are shown between MU2 and $\mathrm{N} 2$ (equal to 0.068 ) and between $\mathrm{Z} 0$ and MM (equal to 0.052 ). Taking into account these results, 8 major constituents (M2, S2, K1, O1, N2, P1, K2 and Q1) were used for the computation of the model. For the southern coasts of the Mediterranean Sea where no tide-gauge data were available the tidal parameters M2, S2, O1, K1 from Tsimplis et al. (1995) were used at 20 stations (Fig. 2, blue dots).

The vectorial differences $d$ between the resulted amplitudes $a^{o}$ and phases $g^{o}$ and corresponding $a^{m}$ and $g^{m}$ harmonic constants from the global model TPXO7.2 were calculated as vectorial differences using the formula (Foreman et al., 1993)

$d(j)=\left[\left(h_{1}^{o}(j)-h_{1}^{m}(j)\right)^{2}+\left(h_{2}^{o}(j)-h_{2}^{m}(j)\right)^{2}\right]^{1 / 2}$,

where $h_{1}^{o}(j)=a^{o}(j) \cos g^{o}(j), \quad h_{1}^{m}(j)=a^{m}(j) \cos g^{m}(j)$ the in-phase terms for the constituent $j$ of the observation and the model, respectively, and $h_{2}^{o}(j)=$ $a^{o}(j) \sin g^{o}(j), h_{2}^{m}(j)=a^{m}(j) \sin g^{m}(j)$ the corresponding quadrarute terms.

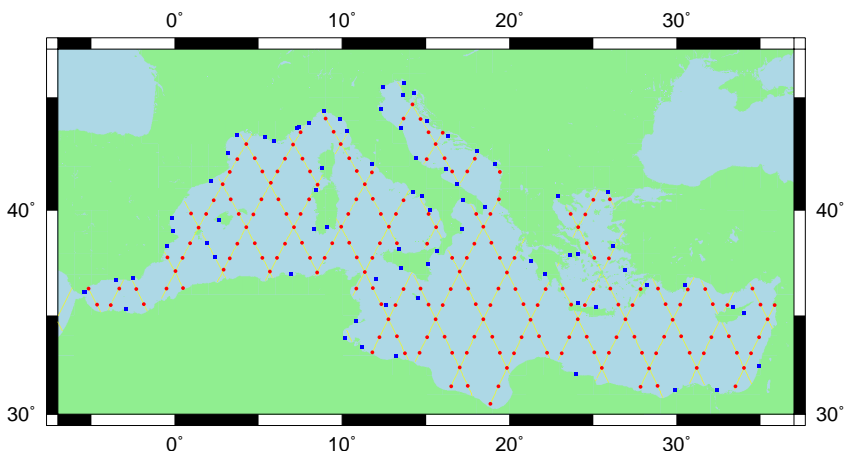

Fig. 3. Representers and data sites used for the computation of MEDI10.

Most of the vectorial differences of the constituents range between 0.3 and $3 \mathrm{~cm}$, thought there are differences exceeding $4 \mathrm{~cm}$ as it is shown in Table 4 . The sites 2, 54, 46, 44, 59, 56 and 57 are located in the Aegean and Adriatic Seas, where global models are not in general able to approximate successfully tides. The sites 3, 13, 20 and 53 are located in the Strait of Gibraltar in very short distances between them (see Fig. 2) and with considerably different vectorial differences. Finally, the sites 30 and 45 are located in Messina Strait.

In the upper part of Table 5, the phases of the tide-gauge observations close to the Strait of Gibraltar are shown. The phases of Tarifa are systematically smaller than the rest, except of O1 (Ceuta) and Q1, while the behavior of changes in Ceuta could be characterized more or less random. In the lower part of the same Table the phases of the observations in the Strait of Messina differ considerably, with that of Messina presenting unusual behavior. Based on the information included in Tables 4 and 5, the observations of Ceuta, Tarifa and Messina were excluded from the computations. The 20 parameters of the constituents M2, S2, K1 and O1 extracted from Tsimplis were used together with the parameters M2, S2, K1, O1, N2, P1, K2 and Q1 of the remaining 56 stations analyzed in the present investigation.

\section{Development of the model}

The model was computed using the FORTRAN 90 package of OTIS. OTIS provides not only elevations but also tidal currents (see Eq. 9). The model grid is $2^{\prime} \times 2^{\prime}$ and the estimated time step is $8 \mathrm{~s}$. TPXO7.2 was used as boundary model. The number of open boundaries was equal to 99 . As representers the crossovers and each 2-nd site along track are selected, as it is shown in Fig. 3. A number of 6 representers lying very close to coasts was rejected. The tide-gauges are added to the selected set of representers . With this selection of the resolution, the representers and the data sites, the potential of our 
Table 3. Correlation coefficients (not diagonal) larger than 0.01 between the constituents of Table 1 . The numbers in parenthesis correspond to the stations of Table 1.

\begin{tabular}{|c|c|c|c|c|c|c|c|c|c|c|c|c|c|}
\hline & $Z_{0}$ & $\mathrm{MF}$ & $\mathrm{MM}$ & Q1 & $\mathrm{O} 1$ & $\mathrm{~K} 1$ & MU2 & $\mathrm{N} 2$ & M2 & $\mathrm{S} 2$ & MK3 & SK3 & S4 \\
\hline \multirow[t]{2}{*}{$Z_{0}$} & - & .033 & .052 & - & - & .019 & . 011. & - & - & - & - & .017 & - \\
\hline & - & (40) & (2) & - & - & (18) & (4) & - & - & - & - & (18) & - \\
\hline \multirow[t]{2}{*}{ MF } & & - & - & .017 & .018 & - & - & - & - & - & - & - & - \\
\hline & & - & - & (18) & (18) & - & - & - & - & - & - & - & - \\
\hline \multirow[t]{2}{*}{$\mathrm{MM}$} & & & - & - & .017 & .013. & - & - & - & - & - & - & - \\
\hline & & & - & - & (8) & (47) & - & - & - & - & - & - & - \\
\hline \multirow[t]{2}{*}{ Q1 } & & & & - & .038 & .036 & - & .015 & - & - & - & - & - \\
\hline & & & & - & (2) & (18) & - & (18) & - & - & - & - & - \\
\hline \multirow[t]{2}{*}{ O1 } & & & & & - & .023 & - & .015 & 015 & - & - & - & - \\
\hline & & & & & - & (40) & - & (8) & (18) & - & - & - & - \\
\hline \multirow[t]{2}{*}{ K1 } & & & & & & - & .012 & - & - & .014 & - & - & - \\
\hline & & & & & & - & (29) & - & - & (18) & - & - & - \\
\hline \multirow[t]{2}{*}{ MU2 } & & & & & & & - & .068 & .030 & .013. & - & - & - \\
\hline & & & & & & & - & (2) & (8) & (4) & - & - & - \\
\hline \multirow[t]{2}{*}{$\mathrm{N} 2$} & & & & & & & & - & .037 & .019. & - & - & - \\
\hline & & & & & & & & - & (2) & (32) & - & - & - \\
\hline \multirow[t]{2}{*}{ M2 } & & & & & & & & & - & .025 & .015 & - & - \\
\hline & & & & & & & & & - & (8) & (18) & - & - \\
\hline \multirow[t]{2}{*}{ S2 } & & & & & & & & & & - & - & .019 & .017 \\
\hline & & & & & & & & & & - & - & (18) & (18) \\
\hline \multirow[t]{2}{*}{ MK3 } & & & & & & & & & & & - & .027 & - \\
\hline & & & & & & & & & & & - & (8) & - \\
\hline \multirow[t]{2}{*}{ SK3 } & & & & & & & & & & & & - & - \\
\hline & & & & & & & & & & & & - & - \\
\hline S4 & & & & & & & & & & & & & - \\
\hline
\end{tabular}

Table 4. Vectorial differences (formula 17) exceeding $4 \mathrm{~cm}$ between observed constituents and TPXO7.2. The last three rows are related to data taken from Tsimplis et al. (1995). Unit is $\mathrm{cm}$.

\begin{tabular}{llcccccccc}
\hline & Site & M2 & S2 & K1 & O1 & N2 & P1 & K2 & Q1 \\
\hline 2 & Alexandroupolis & 4.14 & 2.85 & 0.89 & 0.20 & 1.12 & 0.39 & 0.68 & 0.15 \\
3 & Algeciras & 5.82 & 1.80 & 0.88 & 0.96 & 1.29 & 0.27 & 0.34 & 0.12 \\
13 & Ceuta & 4.77 & 1.05 & 1.70 & 1.47 & 0.93 & 0.60 & 0.09 & 0.16 \\
20 & Gibraltar & 4.12 & 0.13 & 0.65 & 0.49 & 0.15 & 0.20 & 0.16 & 0.09 \\
30 & Messina & 7.13 & 2.10 & 1.00 & 0.58 & 1.20 & 0.32 & 0.52 & 0.23 \\
44 & Ravenna & 4.93 & 3.42 & 5.14 & 3.22 & 1.01 & 2.79 & 1.25 & 0.95 \\
45 & Reggio Calabria & 10.92 & 3.91 & 2.13 & 0.78 & 2.12 & 0.62 & 1.02 & 0.22 \\
46 & Rovinj & 6.87 & 3.90 & 6.56 & 3.27 & 1.55 & 3.19 & 1.70 & 0.90 \\
53 & Tarifa & 15.13 & 4.51 & 1.45 & 1.27 & 2.91 & 0.51 & 1.39 & 0.29 \\
54 & Thessaloniki & 5.28 & 3.28 & 0.72 & 0.30 & 1.01 & 0.40 & 0.81 & 0.14 \\
56 & Trieste & 13.08 & 8.38 & 8.03 & 3.69 & 2.63 & 3.64 & 2.76 & 0.84 \\
57 & Venezia & 9.42 & 6.10 & 6.83 & 3.71 & 1.96 & 3.31 & 2.19 & 0.96 \\
59 & Zadar & 3.60 & 2.12 & 4.04 & 2.05 & 0.26 & 2.17 & 0.33 & 0.52 \\
62 & Gabes & 7.39 & 8.41 & 1.12 & 0.59 & - & - & - & - \\
63 & Sfax & 12.13 & 8.98 & 0.23 & 0.35 & - & - & - & - \\
64 & Zarzis & 4.34 & 1.00 & 0.52 & 0.05 & - & - & - & - \\
\hline
\end{tabular}


Table 5. Phase lag of tide-gauge observations close to Straits of Gibraltar (upper) and Messina (lower).

\begin{tabular}{clcccccccc}
\hline & Site & $\mathrm{M} 2$ & $\mathrm{~S} 2$ & $\mathrm{~K} 1$ & $\mathrm{O} 1$ & $\mathrm{~N} 2$ & $\mathrm{P} 1$ & $\mathrm{~K} 2$ & $\mathrm{Q} 1$ \\
\hline 3 & Algeciras & 47.8 & 74.5 & 130.6 & 169.9 & 34.5 & 128.2 & 66.2 & 195.8 \\
13 & Ceuta & 48.8 & 76.1 & 142.8 & 102.4 & 34.7 & 140.4 & 67.8 & 152.5 \\
20 & Gibraltar & 49.6 & 76.6 & 133.8 & 174.7 & 36.2 & 131.4 & 68.3 & 174.7 \\
53 & Tarifa & 41.0 & 68.5 & 128.2 & 121.1 & 26.0 & 125.8 & 60.2 & 216.8 \\
\hline \multirow{2}{*}{30} & Messina & 347.5 & 12.9 & 271.2 & 46.3 & 342.1 & 268.8 & 4.6 & 46.0 \\
45 & Reggio Calabria & 62.6 & 66.3 & 34.7 & 45.0 & 64.1 & 32.3 & 58.0 & 57.4 \\
\hline
\end{tabular}

Table 6. RMS and RSS of the differences between the solutions using different friction velocity and the observations. Unit is cm.

\begin{tabular}{|c|c|c|c|c|c|c|c|c|c|}
\hline & M2 & $\mathrm{S} 2$ & $\mathrm{~N} 2$ & $\mathrm{~K} 2$ & $\mathrm{~K} 1$ & $\mathrm{O} 1$ & $\mathrm{P} 1$ & Q1 & \\
\hline Number & 76 & 76 & 56 & 56 & 76 & $75^{*}$ & 56 & 56 & \\
\hline Friction velocity & \multicolumn{8}{|c|}{ RMS } & RSS \\
\hline $1 \mathrm{~m} \mathrm{~s}^{-1}$ & 1.067 & 0.750 & 0.322 & 0.233 & 0.816 & 0.425 & 0.423 & 0.176 & 1.707 \\
\hline Varying & 0.955 & 0.646 & 0.295 & 0.311 & 0.565 & 0.322 & 0.232 & 0.187 & 1.423 \\
\hline $2 \mathrm{~ms}^{-1}$ & 1.031 & 0.896 & 0.450 & 0.456 & 0.853 & 0.577 & 0.779 & 0.199 & 1.996 \\
\hline
\end{tabular}

* O1 is missing from station Panteleria, extracted from Tsimplis et al. (1995).

computational system was exhausted. The following default values suggested by Egbert and Erofeeva (2008) were used:

- Fractional bathymetry error 0.05

- Fractional drag error 0.55

- Fractional open boundary error 0.05

- Fractional rigid boundary error 0.2

These values are fractions of the corresponding whole quantities with no units. For instance, fractional error equal to 0.05 on bathymetry means that for a model depth equal to $1000 \mathrm{~m}$ the error will be equal to $0.05 \times 1000=50 \mathrm{~m}$. All these parameters are used when calculating dynamic covariance.

The evaluation of the essential parameters, friction velocity and decorrelation length scale i.e. the distance at which model field values are not correlated, was carried out after some numerical experiments. More specifically, for the evaluation of the friction velocity experiments were conducted using constant equal to $1 \mathrm{~m} \mathrm{~s}^{-1}$, spatially varying, and constant equal to $2 \mathrm{~m} \mathrm{~s}^{-1}$. The spatially varying velocity was estimated as a function of position in the model domain using the method suggested by Zaron and Egbert (2006). According to this method, the drag tensor components at the latitudes and longitudes of the $U$ and $V$ nodes are calculated using transport fields from a prior model. For solution of the inverse problem non-linearity in the dynamical equations due to quadratic bottom drag is linearized in the neighborhood of the prior tidal solution. This leads to solving linear dynamical equations with a linearized drag tensor computed from the velocities from the prior solution. In these three numerical experiments the number of representers was 268 .

For the evaluation of the results, the in-phase and quadrature terms of each constituent from each solution as well as from the observed data, were computed and compared in terms of the RMS deviation of amplitude defined by

$$
\begin{aligned}
\operatorname{RMS}_{j} & =\left(\frac{1}{2 N} \sum_{i=1}^{N}\left[h_{1}^{m}(i, j)-h_{1}^{o}(i, j)\right)^{2}\right. \\
& \left.+\left[h_{2}^{m}(i, j)-h_{2}^{o}(i, j)\right]^{2}\right)^{1 / 2},
\end{aligned}
$$

where $h_{1}^{m}(i, j), h_{1}^{o}(i, j), h_{2}^{m}(i, j), h_{2}^{o}(i, j)$ are the in-phase and quadrature amplitudes of the model and tide-gauge data, respectively, for each location $i$ and constituent $j$, and $N$ is the total number of locations where the in-phase and quadrature amplitudes are computed.

Furthermore the Root Sum of Squares (RSS) was computed, which accounts for the total effect of the $n$ major constituents for each model against the tide-gauge observations, defined by

$\mathrm{RSS}=\left(\sum_{j=1}^{n} \mathrm{RMS}_{j}^{2}\right)^{1 / 2}$

The results in terms of RMS and RSS are shown in Table 6. It is evident that the solution with varying friction velocity 
Table 7. RMS and RSS of the differences between the control data set (i), not used in the assimilation and the solutions computed with different decorrelation lengths. Famagusta control station includes 4 constituents. Unit is $\mathrm{cm}$.

\begin{tabular}{|c|c|c|c|c|c|c|c|c|c|c|}
\hline & & M2 & S2 & $\mathrm{N} 2$ & $\mathrm{~K} 2$ & K1 & $\mathrm{O} 1$ & $\mathrm{P} 1$ & Q1 & \\
\hline Number & & 10 & 10 & 9 & 9 & 10 & 10 & 9 & 9 & \\
\hline Solution & $\begin{array}{l}\text { Correlation } \\
\text { length }(\mathrm{km})\end{array}$ & \multicolumn{8}{|c|}{ RMS } & RSS \\
\hline $\mathrm{a}$ & 10 & 1.800 & 1.431 & 2.741 & 2.858 & 3.581 & 2.270 & 14.718 & 2.179 & 16.134 \\
\hline b & 20 & 0.483 & 0.411 & 0.194 & 0.261 & 0.281 & 0.159 & 0.128 & 0.139 & 0.805 \\
\hline $\mathrm{c}$ & 25 & 0.488 & 0.401 & 0.229 & 0.244 & 0.241 & 0.168 & 0.145 & 0.147 & 0.800 \\
\hline $\mathrm{d}$ & 30 & 0.480 & 0.414 & 0.191 & 0.261 & 0.319 & 0.160 & 0.134 & 0.147 & 0.821 \\
\hline $\mathrm{e}$ & 35 & 0.481 & 0.415 & 0.190 & 0.261 & 0.339 & 0.161 & 0.134 & 0.148 & 0.830 \\
\hline $\mathrm{f}$ & 40 & 0.489 & 0.400 & 0.209 & 0.245 & 0.273 & 0.167 & 0.147 & 0.148 & 0.806 \\
\hline
\end{tabular}

is better than the solutions using constant velocities equal to $1 \mathrm{~m} \mathrm{~s}^{-1}$ and $2 \mathrm{~m} \mathrm{~s}^{-1}$, respectively. For this reason, the next experiments related with the evaluation of the correlation length scales were carried out using varying friction velocity.

Specification of the dynamical error covariance $\Sigma_{f}$ (see, Eq. 3) is a critical part of the inverse problem. The correlation length scales (interior, open boundaries $(\mathrm{OB})$ and length scale for covariance) affect first of all covariance and depend on the area specifics (first of all topography) (Erofeeva, personal communication). The general form of the covariance used in OTIS is described in details by (Egbert et al., 1994, see, page 24829 ). To estimate the optimum interior decorrelation length scale, numerical experiments were carried out using spatially varying friction velocity and changing the decorrelation length. Solutions using (a) 10, (b) 20, (c) 25, (d) 30, (e) 35 and (f) $40 \mathrm{~km}$ were examined. Note that the value of $30 \mathrm{~km}$ corresponds to about $10 \times s \mathrm{~km}$, where $s$ the mean side length of our $2^{\prime} \times 2^{\prime}$ grid resolution.

In all cases (a) to (f) the OB length scale was taken equal to ten times the interior decorrelation length scale, since relatively few $\mathrm{OB}$ exist in Mediterranean so that tuning OB length scale does not make much sense.

To evaluate the results of these experiments, it was suggested to select a number of control tide-gauge stations that will not be used for assimilation. Since there is a question about the selection of the test gauges, two control data sets were selected, consisting each of 10 different stations. In control data set (i) the tide-gauges Carloforte, La Spezia, Napoli, Vieste, Split, Toulon, Porto Vedres, Motril2, Rafina and Famagusta, shown as filled squares in Fig. 2, while in (ii) the tide-gauges Algeciras, Bakar, Civitavecchia, Imperia, Palermo, Porto Torres, Pireas, Ravena, Sfax and Portsaid, shown as filled triangles in Fig. 2 are included. In both data sets the control stations were selected to be homogeneously distributed and possibly to not disturb the distribution of the rest stations to be used for assimilation. In this way from the set of 76 sites only 66 were used for assimilation during the experiments for the estimation of the optimal decorrelation length scale.

The results of these experiments in terms of RMS and RSS differences between the constituents of the data set (i) and the corresponding constituents from the solutions (a) to (f) described above are shown in Table 7. These results suggest that a decorrelation length scale equal to $25 \mathrm{~km}$ is optimum for the Mediterranean Sea. The experiment with the very short length of $10 \mathrm{~km}$ resulted in very large values of both RMS and RSS. On the other hand, the results are not so sensitive for lengths between 20 and $40 \mathrm{~km}$.

Using the same spatially varying friction velocity and decorrelation length scale as for the solution (c), but as control data the tide-gauges of set (ii), a new solution (g) was computed. The comparison of the constituents of solution (g) with the constituents of the control data-set (ii) is shown in Table 8.

The comparison of the results of Table 7 for the solution (c) with that of Table 8 for the solution (g) shows that tide-gauges played a very critical role on the behavior of the model.

For the assessment of the up to now results, the constituents of the control set (i) were compared with corresponding constituents extracted from the models referred in Sect. 3 and from the solution (c) of Table 7. The results in terms of RMS and RSS discrepancies are shown in Table 9.

The results of the comparison between the constituents of the control set (ii) with corresponding constituents extracted from the models referred in Sect. 3 and from the solution (g) of Table 8 are shown in Table 10.

Table 9 shows that in terms of RMS and RSS the solution (c) agrees better with the constituents of the control data-set (i) than all global models but not than the regional model MED2008. From this result, it might be supposed that some or all of the control data set (i) have been assimilated in MED2008. However, the values of the parameters amplitude 
Table 8. RMS and RSS of the differences between the constituents of the control data set (ii) and the solution (g). Solution (g) does not assimilate any tide-gauge from the control set (ii). Sfax and Portsaid include 4 constituents. Unit is $\mathrm{cm}$.

\begin{tabular}{|c|c|c|c|c|c|c|c|c|c|c|}
\hline & & M2 & S2 & $\mathrm{N} 2$ & K2 & K1 & $\mathrm{O} 1$ & $\mathrm{P} 1$ & Q1 & \\
\hline Number & & 10 & 10 & 8 & 8 & 10 & 10 & 8 & 8 & \\
\hline Solution & $\begin{array}{l}\text { Correlation } \\
\text { length }(\mathrm{km})\end{array}$ & \multicolumn{8}{|c|}{ RMS } & RSS \\
\hline $\mathrm{g}$ & 25 & 4.792 & 2.618 & 0.418 & 0.242 & 0.527 & 0.342 & 0.342 & 0.258 & 5.545 \\
\hline
\end{tabular}

Table 9. RMS and RSS of the differences between the constituents of the control data set (i), the solution (c) of Table 7, and contemporary global and regional tide models. Unit is $\mathrm{cm}$.

\begin{tabular}{|c|c|c|c|c|c|c|c|c|c|}
\hline & M2 & $\mathrm{S} 2$ & $\mathrm{~N} 2$ & $\mathrm{~K} 2$ & K1 & O1 & P1 & Q1 & \\
\hline Number & 10 & 10 & 9 & 9 & 10 & 10 & 9 & 9 & \\
\hline Model & \multicolumn{8}{|c|}{ RMS } & RSS \\
\hline Solution (c) & 0.488 & 0.401 & 0.229 & 0.244 & 0.241 & 0.168 & 0.145 & 0.147 & 0.800 \\
\hline EOT10a & 2.778 & 1.099 & 0.620 & 0.432 & 0.609 & 0.343 & 0.208 & 0.145 & 3.170 \\
\hline GOT4.7 & 2.784 & 1.004 & 0.751 & 0.387 & 0.644 & 0.292 & 0.209 & 0.139 & 3.168 \\
\hline NAO99b & 2.998 & 1.150 & 0.668 & 0.346 & 3.904 & 0.438 & 0.352 & 0.170 & 3.470 \\
\hline FES2004 & 2.921 & 1.109 & 0.802 & 0.346 & 0.869 & 0.530 & 0.280 & 0.238 & 3.422 \\
\hline ТPXO7.2 & 0.725 & 1.027 & 0.382 & 0.343 & 3.532 & 0.312 & 0.275 & 0.177 & 1.527 \\
\hline MED2008 & 0.422 & 0.379 & 0.125 & 0.142 & 0.270 & 0.170 & 0.151 & 0.093 & 0.701 \\
\hline
\end{tabular}

and phase in one tide-gauge station depend on the length of the time series, the quality and the gaps probably included in the data and the method of analysis. Taking this into account and that the RSS difference between solution (c) and MED2008 is very small, it could also be supposed that both, solution (c) and MED2008 are using the same tide-gauge stations, with different values of the parameters, but data from the control data-set (i) were not used in the solution (c).

Table 10 shows that the solution $(\mathrm{g})$ has yielded better RMS and RSS values than MED2008, although data from the control data-set (ii) was not used in the solution (g). Now, it might be supposed that none or some of the control dataset (ii) was assimilated in MED2008. On the other hand, from Table 10 it is shown that in terms of RSS, TPXO7.2 agree better with the constituents of the control data-set (ii) than MED2008 and our solution (g), although it is not reported that tide-gauges data are assimilated in this model in the Mediterranean Sea.

Our conclusion from the experiments described above is that the data played a very critical role for the quality of a model and thus we suggest a model referred to as MEDI10, which used all available data (except the 3 rejected tidegauges of Ceuta, Tarifa and Messina), and the parameters estimated experimentally. In Fig. 3, the distribution of the representers (red from altimetry, blue from tide-gauges) and data sites (yellow) are shown.
The RMS and RSS misfit according to formulas 18 and 19 between the observed 76 and corresponding MEDI10 amplitudes and phases are shown in Table 11. These results, as a criterion of fit to the assimilated data, can be considered satisfactory taking into account the results of Tables 9 and 10 .

An approach to validate MEDI10 is to use an independent data set of tidal amplitude and phase resulting at crossover locations from TOPEX/Poseidon and more recent satellite missions. Since the residual tide analysis for EOT10a was carried out with altimeter data of TOPEX/Poseidon, ERS-2, Jason-1, Jason-2 and ENVISAT, it was considered as ideal source for the extraction of amplitude and phase parameters at the 39 crossover locations lying over the Mediterranean Sea. The comparison of MEDI10 with TPXO7.2, GOT4.7, NAO99b, FES2004 and MED2008 is shown in Table 12.

Table 12 showed that TPXO7.2 agreed better with EOT10a, not only than the global but also than the regional models MED2008 and MEDI10. This is obviously due to the fact that both are using the same satellite data except ENVISAT that are used only in EOT10a. On the other hand, regional solutions assimilated tide-gauge data include more local information, so that differences between global and regional solutions are reasonable. However, the results of Tables 9 and 10 showed that TPXO7.2 does not agree with the control data-set (i) and MED2008 does not agree with 
Table 10. RMS and RSS of the differences between the constituents of the control data set (ii), the solution (g) of Table 8, and contemporary global and regional tide models. Unit is $\mathrm{cm}$.

\begin{tabular}{|c|c|c|c|c|c|c|c|c|c|}
\hline & M2 & $\mathrm{S} 2$ & $\mathrm{~N} 2$ & $\mathrm{~K} 2$ & K1 & $\mathrm{O} 1$ & P1 & Q1 & \\
\hline Number & 10 & 10 & 9 & 9 & 10 & 10 & 9 & 9 & \\
\hline Model & \multicolumn{8}{|c|}{ RMS } & RSS \\
\hline Solution (g) & 4.792 & 2.618 & 0.418 & 0.242 & 0.627 & 0.342 & 0.342 & 0.258 & 5.545 \\
\hline EOT10a & 7.050 & 3.053 & 1.550 & 0.918 & 0.609 & 0.343 & 0.208 & 0.145 & 8.286 \\
\hline GOT4.7 & 7.346 & 3.328 & 1.573 & 0.774 & 2.125 & 0.990 & 0.906 & 0.289 & 8.508 \\
\hline NAO99b & 7.702 & 3.990 & 1.515 & 0.747 & 1.189 & 0.870 & 0.493 & 0.220 & 8.976 \\
\hline FES2004 & 7.383 & 3.235 & 1.553 & 0.899 & 2.267 & 1.091 & 1.060 & 0.343 & 8.704 \\
\hline TPXO7.2 & 3.387 & 2.254 & 0.486 & 0.388 & 1.693 & 1.045 & 0.928 & 0.326 & 4.676 \\
\hline MED2008 & 4.147 & 2.348 & 0.588 & 0.483 & 3.341 & 1.086 & 1.285 & 0.210 & 6.109 \\
\hline
\end{tabular}

Table 11. RMS and RSS misfit between the observed 76 and corresponding MEDI10 amplitude and phases. Unit is $\mathrm{cm}$.

\begin{tabular}{|c|c|c|c|c|c|c|c|c|c|c|}
\hline & M2 & S2 & N2 & $\mathrm{K} 2$ & K1 & $\mathrm{O} 1$ & $\mathrm{P} 1$ & Q1 & & \\
\hline & 76 & 76 & 56 & 56 & 76 & 75 & 56 & 56 & & \\
\hline RMS & 0.828 & 0.592 & 0.506 & 0.316 & 0.268 & 0.217 & 0.285 & 0.180 & RSS & 1.275 \\
\hline
\end{tabular}

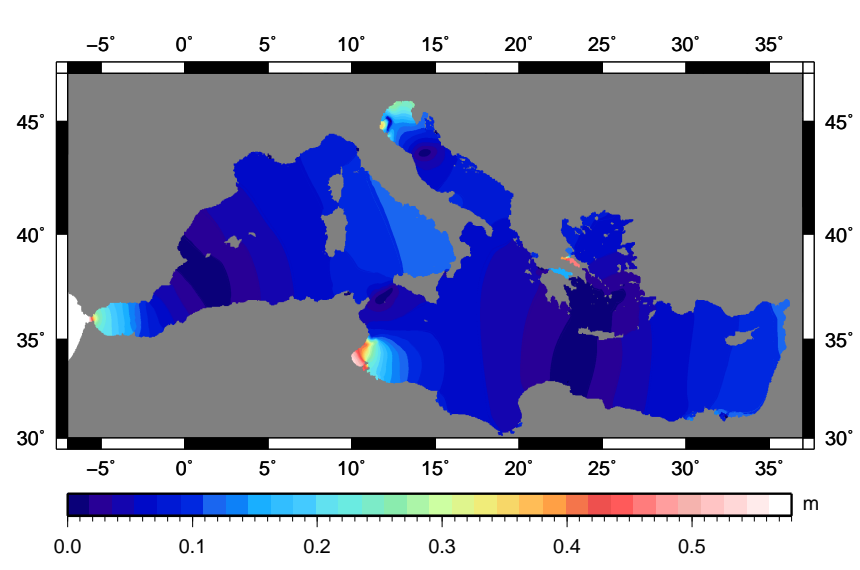

Fig. 4. Amplitude of the M2 constituent.

the control data-set (ii). Taking into account that these data are included in our final solution MEDI10, the results of Table 12 could not be used in ranking MEDI10, with respect to TPXO7.2 and MED2008.

Furthermore, the results of Table 12 suggest that an improvement of our model could be achieved adding data from other satellites such as Jason-1, Jason-2, ENVISAT and from the very promising for enclosed seas PISTACH project.

Figure 4 shows the computed amplitude of the M2 tide. The amplitude in the most part of the basin is less than $10 \mathrm{~cm}$, with the exception of the Gulf of Gabes $(53 \mathrm{~cm})$, the north

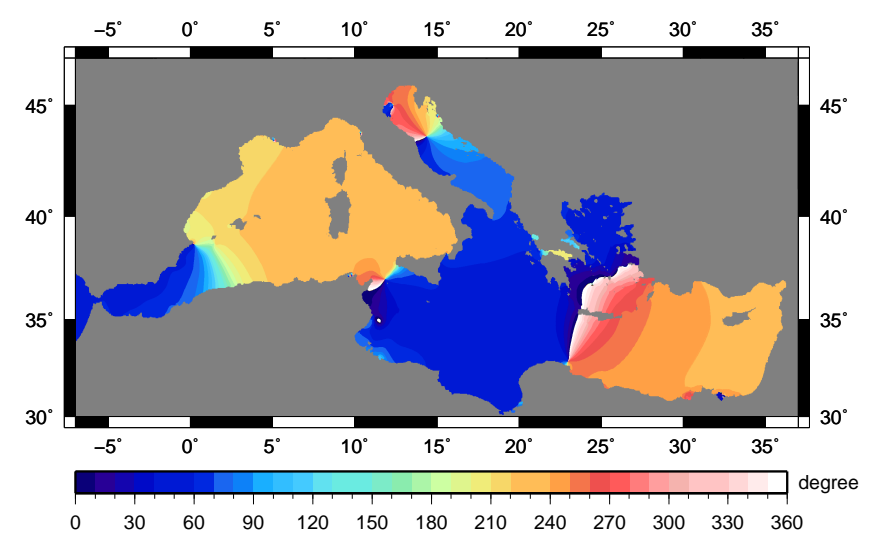

Fig. 5. Phase of the M2 constituent (degrees relative to UTC).

Adriatic $(22 \mathrm{~cm})$ and the strait of Gibraltar $(40 \mathrm{~cm})$. Figure 6 shows the amplitude of $\mathrm{S} 2$ tide. In this figure, the amplitude pattern is very similar to those of M2 but with reduced amplitudes. Figure 8 shows the computed amplitude of the major diurnal $\mathrm{K} 1$ tide. It is noteworthy the large amplitude of $16 \mathrm{~cm}$ existing only in the Adriatic Sea. Finally, the amplitude of the diurnal $\mathrm{O} 1$ is shown in Fig. 10. Maximum values up to $0.05 \mathrm{~m}$ of $\mathrm{O} 1$ appeared in the North Adriatic.

The phases for M2, S2, K1 and $\mathrm{O} 1$ are shown in Figs. 5, 7,9 , and 11 respectively. The position of the amphidromes appearing in these figures was located using the Tide Model 
Table 12. RMS and RSS of the differences between the constituents of the empirical model EOT10a at crossovers over Mediterranean, and other contemporary global and regional tide models. Unit is $\mathrm{cm}$.

\begin{tabular}{|c|c|c|c|c|c|c|c|c|c|}
\hline & M2 & S2 & $\mathrm{N} 2$ & $\mathrm{~K} 2$ & K1 & $\mathrm{O} 1$ & $\mathrm{P} 1$ & Q1 & \\
\hline Number & 39 & 39 & 39 & 39 & 39 & 39 & 39 & 39 & \\
\hline Model & \multicolumn{8}{|c|}{ RMS } & RSS \\
\hline ТРХО7.2 & 0.479 & 0.399 & 0.264 & 0.264 & 0.456 & 0.320 & 0.283 & 0.172 & 0.974 \\
\hline GOT4.7 & 0.698 & 0.623 & 0.299 & 0.327 & 0.305 & 0.188 & 0.220 & 0.121 & 1.123 \\
\hline NAO99b & 0.913 & 0.960 & 0.309 & 0.484 & 0.830 & 0.344 & 0.324 & 0.136 & 1.736 \\
\hline FES2004 & 1.077 & 0.469 & 0.353 & 0.310 & 0.436 & 0.393 & 0.240 & 0.203 & 1.430 \\
\hline MED2008 & 0.583 & 0.404 & 0.332 & 0.256 & 0.445 & 0.215 & 0.159 & 0.096 & 0.978 \\
\hline MEDI10 & 0.619 & 0.447 & 0.328 & 0.340 & 0.415 & 0.234 & 0.169 & 0.126 & 1.062 \\
\hline
\end{tabular}

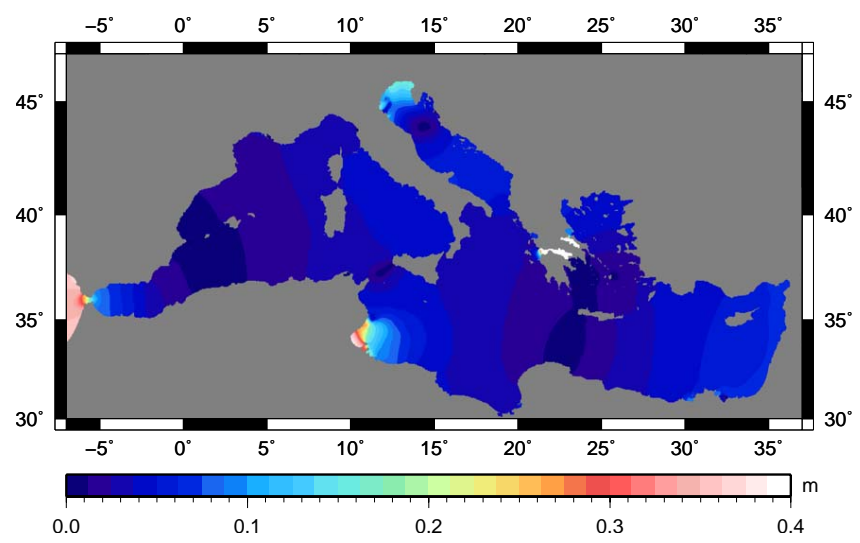

Fig. 6. Amplitude of the S2 constituent.

Driver (TMD) Matlab Toolbox (personal communication, L. Padman and S. Erofeeva, 2010). Their coordinates in MEDI10 are shown in Table 13. For the sake of comparison, the coordinates of MED2008 amphidromes as well the spherical distances in $\mathrm{km}$ between respective amphidromes are included in the same Table. Furthermore, amphidromes comparison with Tsimplis et al. (1995) model was carried out based on the corresponding figures, because the latter model is not available in digital form. In Fig. 5, two amphidromes for M2 are clearly defined: the first one in the Strait of Sicily and the second in the north Adriatic. The positions of these two amphidromes are in agreement with the model by Tsimplis et al. (1995) as well as with MED2008 (see Table 13). The amphidrome appearing in the western basin close to the coast of Spain is in agreement with MED2008, but disagree with the corresponding by Tsimplis et al. (1995), which is far away from the coast. The degenerate amphidrome between the north coast of Africa and Crete is in agreement with Tsimplis et al. (1995) but not with MED2008. In Fig. 7, the distance of the locations of the S2 amphidromes appearing in the Strait of Sicily and Adriatic was increased to more

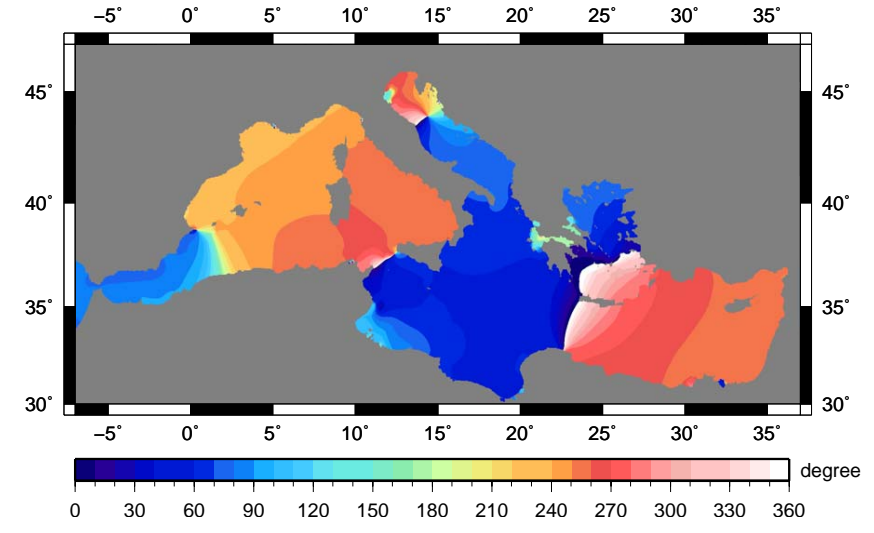

Fig. 7. Phase of the S2 constituent (degrees relative to UTC).

than $20 \mathrm{~km}$, while in the western basin remains below $10 \mathrm{~km}$. The amphidrome between Africa and Crete is no visible in MEDI10. With respect to model by Tsimplis et al. (1995) the agreement is very good in the case of the amphidromes in the Strait of Sicily, Adriatic and Africa, and better than before with that of the western basin. For K1 there is only one amphidrome located at the Strait of Sicily (Fig. 9). Its distance from the corresponding of MED2008 is $45 \mathrm{~km}$. Much better is the agreement with Tsimplis et al. (1995). Finally for O1 (Fig. 11) an amphidrome point is appeared close to coast of Africa. The distance to the corresponding of MED2008 is $62 \mathrm{~km}$. It is not appeared in Tsimplis et al. (1995). Summarizing this discussion, three amphidromes exist in S2 in similar locations to those of M2 but shifted slightly northward. For K1 there is only the amphidrome in the Strait of Sicily, shifted southward. This behavior is the same in MEDI10, MED2008 and Tsimplis et al. (1995). The degenerate amphidrome suggested by MEDI10 and MED2008 it is not as well defined. The existence of the three amphidromes in the three models discussed above suggests that these are real. 
Table 13. Comparison of the position of amphidromes appeared in MEDI10 and MED2008.

\begin{tabular}{|c|c|c|c|c|c|}
\hline \multicolumn{6}{|c|}{ M2 } \\
\hline & \multicolumn{2}{|c|}{ MEDI10 } & \multicolumn{2}{|c|}{ MED2008 } & \multirow{2}{*}{$\begin{array}{c}\text { Distance } \\
\mathrm{km}\end{array}$} \\
\hline & $\varphi^{\circ}$ & $\lambda^{\circ}$ & $\varphi^{\circ}$ & $\lambda^{\circ}$ & \\
\hline Str. of Sicily & 37.02 & 11.82 & 36.95 & 11.85 & 8.2 \\
\hline Adriatic & 43.65 & 14.35 & 43.62 & 14.22 & 11.0 \\
\hline Spain & 38.72 & 00.22 & 38.68 & 00.22 & 4.5 \\
\hline Africa & 32.89 & 22.95 & 32.68 & 22.92 & 23.5 \\
\hline \multicolumn{6}{|c|}{$\mathrm{S} 2$} \\
\hline Str. of Sicily & 37.58 & 12.35 & 37.41 & 12.15 & 25.9 \\
\hline Adriatic & 43.92 & 14.38 & 43.95 & 14.12 & 21.1 \\
\hline Spain & 38.75 & 00.38 & 38.82 & 00.31 & 9.9 \\
\hline Africa & - & - & 32.95 & 22.62 & - \\
\hline \multicolumn{6}{|c|}{ K1 } \\
\hline Str. of Sicily & 36.22 & 12.52 & 35.82 & 12.62 & 45.4 \\
\hline Adriatic & - & - & - & - & - \\
\hline Spain & - & - & - & - & - \\
\hline Africa & - & - & - & - & - \\
\hline \multicolumn{6}{|c|}{$\mathrm{O} 1$} \\
\hline Str. of Sicily & - & - & - & - & - \\
\hline Adriatic & - & - & - & - & - \\
\hline Spain & - & - & - & - & - \\
\hline Africa & 33.52 & 21.48 & 33.12 & 21.02 & 61.7 \\
\hline
\end{tabular}

There is a question whether or not the resonance feature appearing in the Gulf of Gabes is mostly driven by the tide gauges. In Fig. 12, this feature was mapped using the global empirical tide model EOT10a. Comparing this figure with Fig. 4 we see that the same feature appears in both, the empirical EOT10a and MEDI10 which assimilates the tide-gauge of Gabes.

As it was stated in Sect. 5, OTIS provides not only elevations but also tidal currents. The estimation and monitoring of the mass exchange between the Atlantic Ocean and the Mediterranean Sea is essential in calculating the water budget of the Mediterranean basin (Kinder and Bryden, 1990). The surface flow through the Strait carries Atlantic water into the Mediterranean Sea. After passing through the Mediterranean system, it flows back into the Atlantic Ocean at the bottom of the Strait (Baschek et al., 2001). The Mediterranean outflow aspirates the Mediterranean basin and is a source of denser and more saline waters affecting the circulation of the North Atlantic (Price and Baringer, 1994; Tsimplis and Bryden, 2000). The mean flow through the Strait of Gibraltar is modified due to various effects, such as currents which are driven by the wind or atmospheric pressure differences between the Atlantic and Mediterranean Sea (Candela et al., 1989).

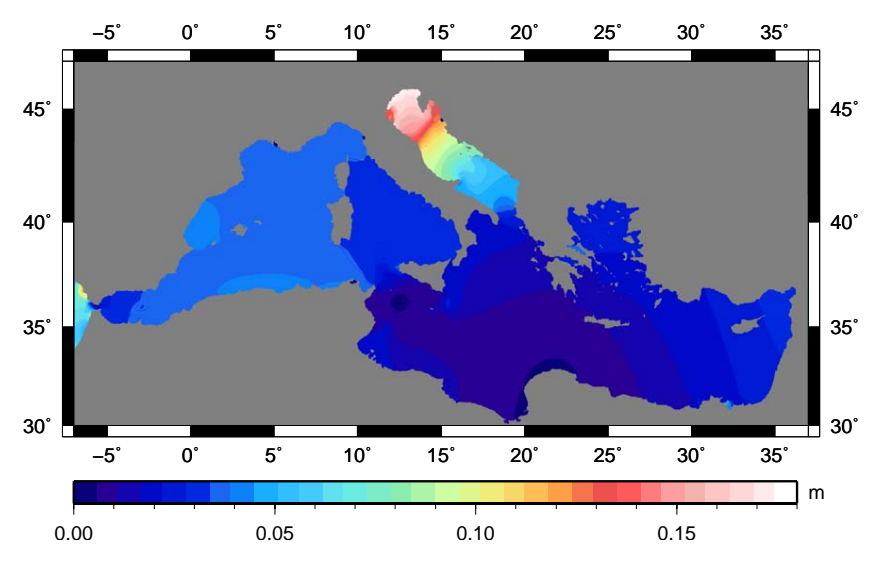

Fig. 8. Amplitude of the K1 constituent.

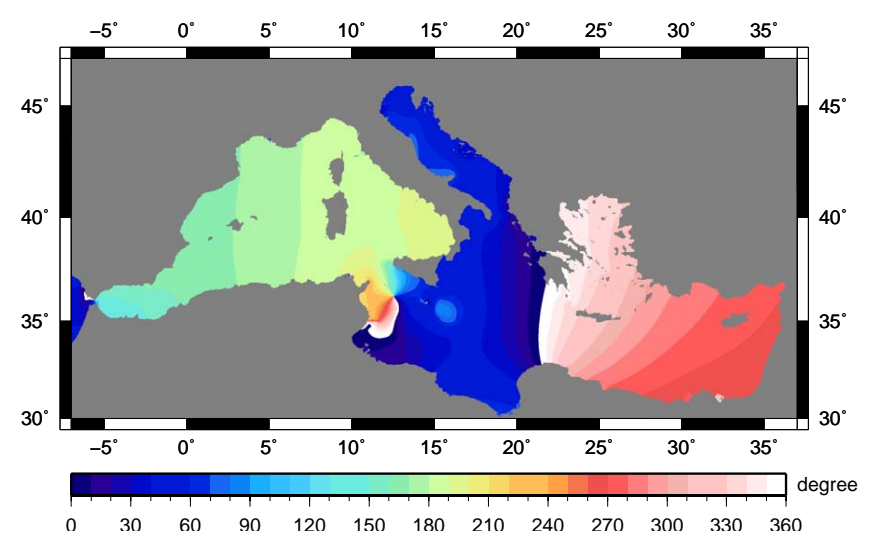

Fig. 9. Phase of the K1 constituent (degrees relative to UTC).

During the Canary Islands Azores Gibraltar Observations (CANIGO) project, Acoustic Doppler Current Profiler (ADCP) measurements were carried out focused on monitoring the currents and the depth of the interface between Atlantic and Mediterranean water. In the framework of this project, varying number of current meter moorings were maintained at the eastern entrance of the Strait between October 1994 and April 1998, complemented with intensive shipboard measurements. According to the estimation by Baschek et al. (2001) the surface amplitude of M2 current at the eastern entrance of the strait is $18 \mathrm{~cm} \mathrm{~s}^{-1}$. At the middle of the ADCP section $\left(\varphi=36^{\circ}, \lambda=-5.22^{\circ}\right)$ the amplitude of the M2 current from MEDI10 is $18.42 \mathrm{~cm} \mathrm{~s}^{-1}$.

Figures 13 and 14 show the transport ellipses of M2 and S2 constituents, respectively. In Fig. 13 considerable large values are observed for M2 at the Strait of Gibraltar (max $270 \mathrm{~m}^{2} \mathrm{~s}^{-1}$ ) as well as in the Sicilian Channel, and S-W Crete. Similar patterns but with reducing amplitudes (max $80 \mathrm{~m}^{2} \mathrm{~s}^{-1}$ at the Strait of Gibraltar) are shown in Fig. 14 for $\mathrm{S} 2$ constituent. 


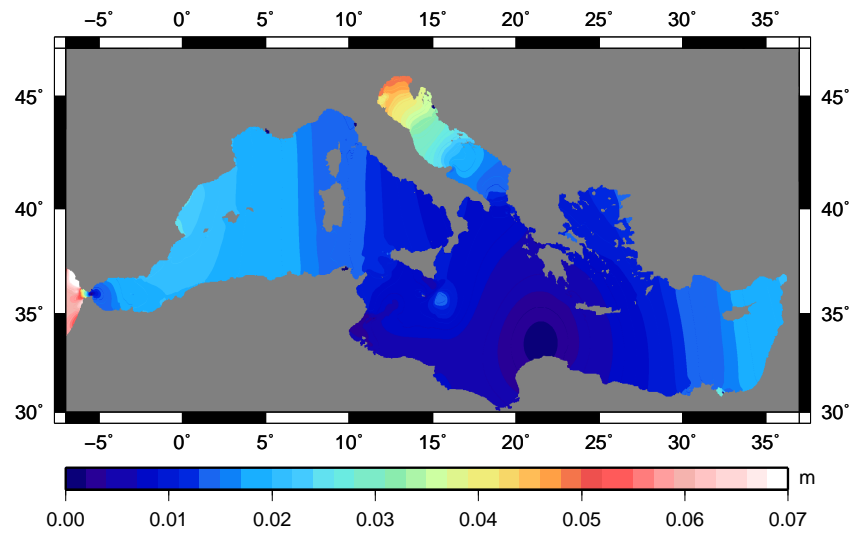

Fig. 10. Amplitude of the $\mathrm{O} 1$ constituent.

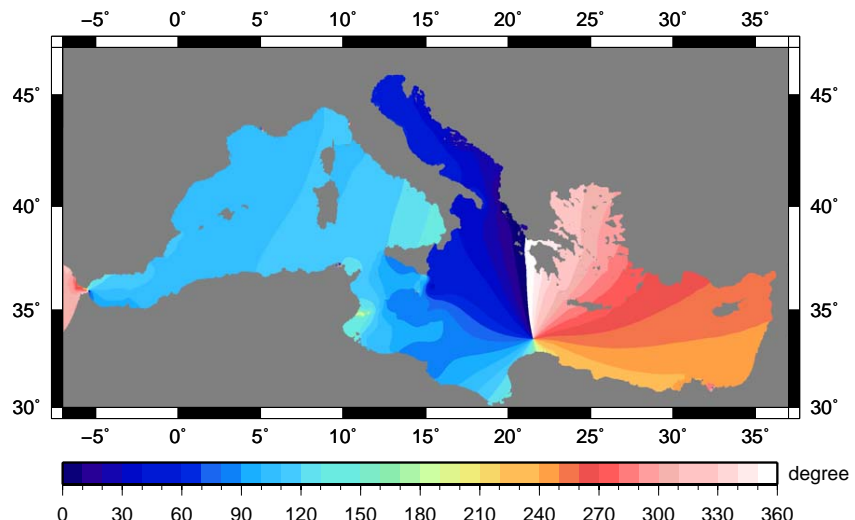

Fig. 11. Phase of the $\mathrm{O} 1$ constituent (degrees relative to UTC).

\section{Summary and conclusions}

A regional $2^{\prime} \times 2^{\prime}$ tide model for the Mediterranean Sea was computed using bathymetry, altimeter data and data from coastal tide-gauge stations. The method used for the computation of the model was the inverse modeling of barotropic ocean tides. Tide-gauge data were selected from different national or international organizations. The analysis of these observations was carried out using the "Versatile Harmonic Tidal Analysis" software.

The problems in this study were caused by the lack of adequate number of tide-gauges around the east and south parts of the Mediterranean coasts and by discrepancies between the tidal parameters of neighboring stations. Numerical experiments showed that in the Mediterranean Sea the solution is sensitive to friction velocity and spatial varying friction velocity yields better results in terms of the RSS discrepancies between the tidal constituents from the tide-gauge observations and from the model. Experiments related to the

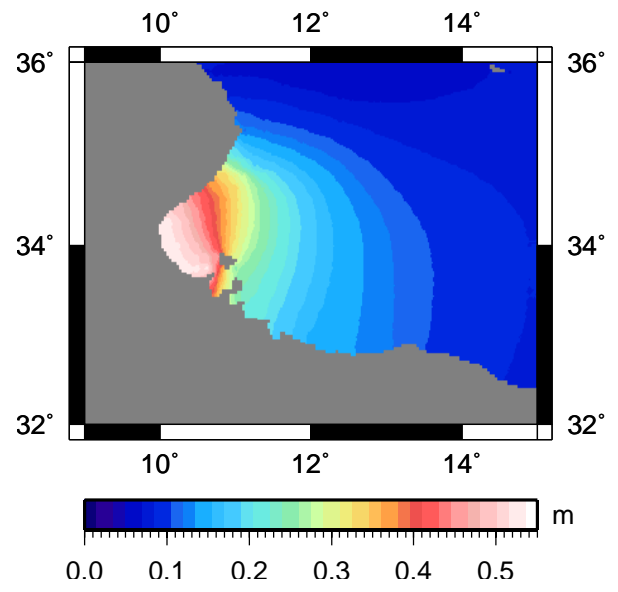

Fig. 12. Mapping of M2 constituent in the Gulf of Gabes from the empirical model EOT10a.

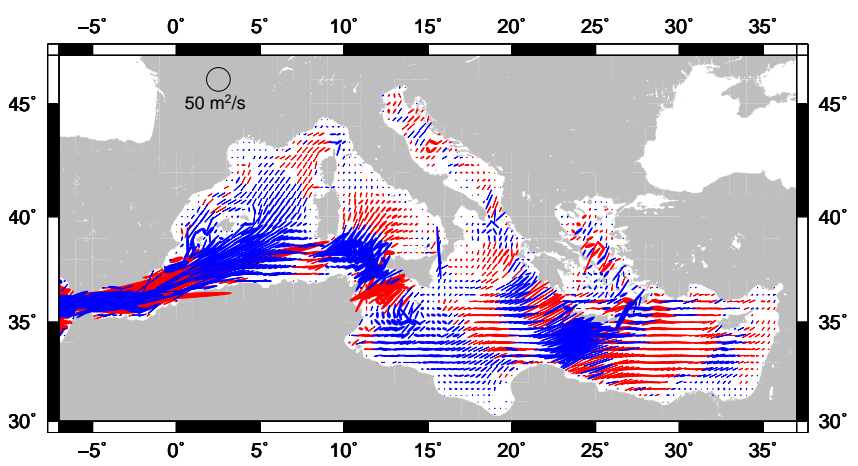

Fig. 13. Transport ellipses of M2 constituent. Red = clockwise, blue $=$ anticlockwise rotation .

estimation of the optimum decorrelation length scale suggest that the results are not so sensitive for lengths between $10 \times s \pm 10 \mathrm{~km}$, where $s$ the side length of the grid cell.

The intermediate solutions obtained in the framework of the experiments aiming to estimate the optimum decorrelation length scale were compared with two different control data sets, together with five contemporary global and one regional ocean tide models. Useful information was gained from these comparisons about the role of tide-gauge data in the assimilation procedure.

The final solution (MEDI10) was computed using all (76) available tide-gauge data. Its quality assessment was based on comparison of constituents extracted from the empirical global model EOT10a at 36 crossover sites over the Mediterranean Sea, with constituents extracted at the same points from MEDI10 and five global and regional ocean tide models. In terms of RMS and RSS misfit, MEDI10 is better than GOT4.7, NAO99b, FES2004 and its RSS is practically 


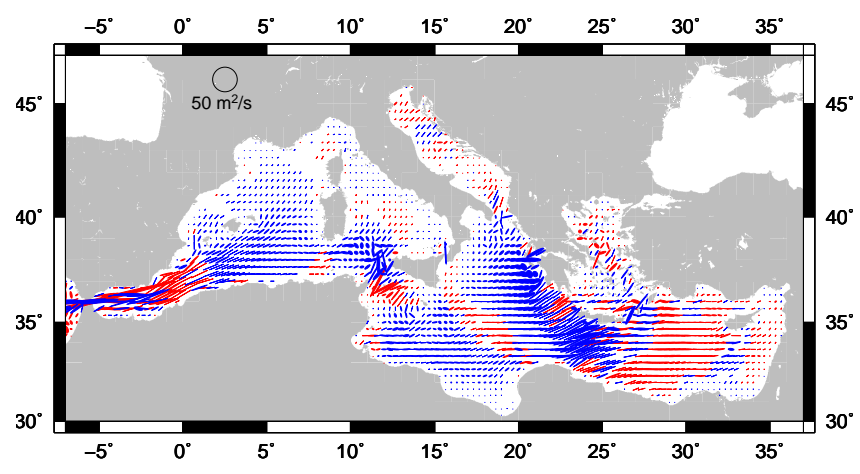

Fig. 14. Transport ellipses of $\mathrm{S} 2$ constituent. Red = clockwise, blue $=$ anticlockwise rotation.

equal to TPXO7.2 and MED2008. Note that TPXO7.2 and MED2008 use not only T/P, as MEDI10 used, but also TP2, ERS GRACE (TPXO7.2) and Jason-1 (MED2008), and therefore are more correlated to EOT10a.

Finally the consistency of MEDI10 with the assimilated tide-dauge data is expressed by an RSS misfit of $1.3 \mathrm{~cm}$.

Acknowledgements. We are very grateful to Svetlana Erofeeva for her continuous support in all phases of this (first for us) experiment and for providing an improved version of OTIS package. Many thanks are due to Mike Foreman and Josef Cherniawsky for providing their tidal analysis packages and Guy Woppelmann for providing French tide-gauge data. The constructive comments by Ole Baltasar Andersen and the unknown reviewers are gratefully acknowledged.

Edited by: A. Schiller

\section{References}

Andersen, O. B., Woodworth, P. L., and Flather, R. A.: Intercomparison of recent ocean tide models. J. Geophys. Res., 100(C12), 25261-25282, 1995.

Arabelos, D.: Comparison of Earth-tide parameters over a large latitude difference. Geoph. J. Int., 950-956, 2002.

AVISO and PODAAC User Handbook: IGDR and GDR Jason Products, 2001.

Baschek, B., Send U., Lafuente, J. G., Candela, J.: Transport estimates in the Strait of Gibraltar with a tidal inverse model. J. Geophys. Res., 106(C12), 31033-31044, 2001.

Bennett, A. F.: Inverse Methods in Physical Oceanography. Monographs on Mechanics and Applied Mathematics, Cambridge University Press, Cambridge, 346 pp., 1992.

Bosch, W. and Savcenko, R.: EOT10a - a new results of empirical ocean tide modelling. Presented at OST Science Team Meeting, Lisbon, Portugal, 18-20 October, 2010.

Candela, J., Winnant, C. D., Bryden, H. L.: Meteorologically forced subinertial flows through the Strait of Gibraltar, J. Geophys. Res., 94, 12667-12679, 1989.
Cartwright, D. E. and Ray, R. D.: Oceanic Tides from Geosat Altimetry, J. Geophys. Res., 95(C3), 3069-3090, 1990.

Cherniawsky, J. Y., Foreman, M. G. G., Crawford, W. R., and Henry, F. R.: Ocean tides from TOPEX/Poseidon Sea Level Data, J. Atmos. Ocean. Techn., 18, 649-664, 2001.

Desai, S. D. and Wahr, J. M.: Empirical ocean tide models estimated from TOPEX/POSEIDON altimetry, J. Geophys. Res., 100(C12), 25205-25228, 1995.

Egbert, G., Bennett, A., and Foreman, M. G. G.: TOPEX/Poseidon tides estimated using a global inverse model, J. Geophys. Res., 99(C12), 24821-24852, 1994.

Egbert, G. and Erofeeva, S.: Efficient inverse modelling of barotropic ocean tides, J. Atmos. Ocean. Tech., 19(2), 183-204, 2002.

Egbert, G. and Erofeeva, S.: Mediterranean inverse tidal solution, http://volkov.oce.orst.edu/tides/region.html, 2008.

Foreman, M. G. G.: Manual for tidal heights analysis and prediction. Pacific Marine Science, Rep. 77-10, Institute of Ocean Sciences, Patricia Bay, Sidney, B.C., pp. 66, 1977.

Foreman, M. G. G.: The harmonic analysis of tidal model time series, Adv. Water Resour., 12, 109-120, 1989.

Foreman, M. G. G. and Henry, R. F.: Tidal analysis based on high and low water observations, Pacific Marine Science Report, 7915, pp. 36, revised, 2004.

Foreman, M. G. G., Henry, R. F., Walters, R. A., and Ballantyne, V. A.: A finite element model for tides and resonance along north coast of British Columbia, J. Geophys. Res., 98, 2509-2531, 1993.

Foreman, M. G. G., Cherniawsky, J. Y., and Ballantyne, V. A.: Versatile harmonic tidal analysis: Improvements and applications, J. Atmos. Ocean. Tech., 26(4), 806-817, 2009.

Kinder, T. H. and Bryden, H. L.: The aspiration of deep waters through Straits, edited by: Pratt, L. J., The Physical Oceanography of Sea Straits, Kluwer, Boston, 295-319, 1990.

Le Provost, C., Genco, M. L., Lyard, P., Vincent, P., and Canceil, P.: Tidal spectroscopy of the world ocean tides from a finite element hydrodynamic model. J. Geophys. Res., 99(C12), 24777-24798, 1994.

Le Provost, C., Bennet, A. F., and Cartwright, D. E.: Ocean tides for and from TOPEX/POSEIDON, Science, New Series, 267(5198), 639-642, 1995.

Le Provost, C., Lyard, F., Molines, J. M., Genco, M. L., and Rabilloud, F.: A hydrodymanic ocean tide model improved by assimilating a satellite altimeter-derived data set, J. Geophys. Res., 103(C3), 5513-5529, 1998.

Lyard, F., Lefevre, F., Letellier, T., and Francis, O.: Modelling the global ocean tides: insights from FES2004, Ocean Dynam., 56, 394-415, 2006.

Martin, P. J., Smith, S. R., Posey P. G., Dawson, G. M., and Riedlinger, S. H.: Use of the Oregon State University Tidal Inversion Software (OTIS) to generate improved tidal prediction in the East-Asian Seas, Stennis Space Center, MS 39529-5004, 2009.

Mazzega, P. and Bergé, M.: Ocean tides in the Asian semienclosed seas from TOPEX/POSEIDON, J. Geophys. Res., 99(C12), 24867-24881, 1994.

Matsumoto, K., Ooe, M., O., Sato, T., and Segawa, J.: Ocean tide model obtained from TOPEX/POSEIDON altimetry data, J. Geophys. Res., 100(C12), 25319-25330, 1995. 
Matsumoto, K., Takanezawa, T., and Ooe, M.: Ocean tide models developed by assimilating TOPEX/Poseidon altimeter data into hydrodynamic model: A global model and a regional model around Japan, J. Oceanogr., 56, 567-581, 2000.

Price, J. F. and O' Neil-Baringer, M.: Outflows and deep water production by marginal seas, Prog. Oceanogr., 33, 157-196, 1994.

Pugh, D. T.: Tides, Surges and Mean Sea-Level, John Wiley and Sons, New York, pp 472, 1987.

Ray, R. D.: A global ocean tide model from TOPEX/Poseidon alrimetry: GOT4.7, NASA Tech. Memo. 209478, Goddard Space Flight Center, Greenbelt, 58 pp, 1999.

Ray, R. D.: GSFC TOPEX/Poseidon "no-tide" data. (rray@ geodesy2.gsfc.nasa.gov), 2002.

Savchenko, R. and Bosch, W.: EOT10a - a new global tide model from multi-mission altimetry. Presented at EGU General Assembly 2010, Vienna, Austria, May 2010.

Schrama, E. J. and Ray, R. D.: A preliminary tidal analysis of TOPEX/POSEIDON altimetry. J. Geophys. Res., 99, C12, 24799-24808, 1994.
Smith, W. H. F. and Sandwell, D. T.: Global seafloor topography from satellite altimetry and ship depth soundings, Science, 277, 1957-1962, 1997.

Shum, C. K., Woodworth, O. B., Egbert, G. D., Francis, O., King, C., Klosko, S. M., Le Provost, C., Li, X., Molines, J.-M., Parke, M. E., Ray, R. D., Schlax, M. G., Stammer, D., Tierney, C. C., Vincent, P., and Wunsch, C. I.: Accuracy assessment of recent ocean tide models. J. Geophys. Res., 102(C11), 25173-25194, 1997.

Tsimplis, M. N., Proctor, R., and Flather, R. A.: A two-dimensional tidal model for the Mediterranean Sea, J. Geophys. Res., 100(C8), 16223-16239, 1995.

Tsimplis, M. N. and Bryden, H. L.: Estimation of the transports through the Strait of Gibraltar, Deep-Sea Res. Pt. I, 47, 2219 2242, 2000.

Zaron, E. D. and Egbert, G. D: Estimating open-ocean barotropic tidal dissipation: The Hawaiian Ridge, J. Phys. Ocean., 36, 1019-1035, 2006. 